\title{
Downscaling Maximum Temperatures to Subkilometer Resolutions in the Shenandoah National Park of Virginia, USA
}

\author{
Temple R. Lee, ${ }^{1}$ Stephan F. J. De Wekker, ${ }^{1}$ and John E. B. Wofford ${ }^{2}$ \\ ${ }^{1}$ Department of Environmental Sciences, Clark Hall, University of Virginia, P.O. Box 400123, Charlottesville, VA 22904-0123, USA \\ ${ }^{2}$ Shenandoah National Park, Luray, VA 22835, USA \\ Correspondence should be addressed to Temple R. Lee; temple@virginia.edu
}

Received 25 April 2014; Accepted 6 August 2014; Published 31 August 2014

Academic Editor: Richard Anyah

Copyright (c) 2014 Temple R. Lee et al. This is an open access article distributed under the Creative Commons Attribution License, which permits unrestricted use, distribution, and reproduction in any medium, provided the original work is properly cited.

\begin{abstract}
Downscaling future temperature projections to mountainous regions is vital for many applications, including ecological and water resource management. In this study, we demonstrate a method to downscale maximum temperatures to subkilometer resolutions using the Parameter-elevation Regression on Independent Slopes Model (PRISM). We evaluate the downscaling method with observations from a network of temperature sensors deployed along western and eastern slopes of Virginia's Shenandoah National Park in the southern Appalachian Mountains. We find that the method overestimates mean July maximum temperatures by about $2^{\circ} \mathrm{C}\left(4^{\circ} \mathrm{C}\right)$ along the western (eastern) slopes. Based on this knowledge, we introduce corrections to generate maps of current and future maximum temperatures in the Shenandoah National Park.
\end{abstract}

\section{Introduction}

General circulation models (GCMs) predict changing temperature and moisture patterns in many regions of the world due to increases in atmospheric carbon dioxide $\left(\mathrm{CO}_{2}\right)$ concentration [1]. The most significant changes are expected at high elevations $[2,3]$ which include the habitats of many endangered species $[4,5]$. One example is the Shenandoah salamander, Plethodon shenandoah (P. shenandoah) whose habitats are located in a $6 \mathrm{~km}^{2}$ area along ridgetops in the Shenandoah National Park (SNP) [6]. There is large uncertainty in how climate change will affect the local climate in these habitats partly because the grid spacing of GCMs, on the order of a few hundred kilometers, cannot resolve the impacts of climate change at local to regional scales [2]. Even regional climate models (RCMs) with resolutions of a few tens of kilometers are still too coarse to assess the effects of climate change on the scale of local habitats. For example, a $50 \mathrm{~km}$ grid spacing typical of RCMs $[7,8]$ averages the elevation changes across the grid, thereby smoothing the topography in mountainous regions [9] including the Blue Ridge Mountains in and around SNP. This topographic smoothing makes it very difficult to understand projected climate changes in these mountainous regions.
To reduce the uncertainty of climate change projections in mountainous regions, RCMs must be further downscaled which is done using either dynamical and/or statistical techniques $[10,11]$. Dynamical downscaling techniques use highresolution meteorological models which are computationally intensive and can have difficulties resolving atmospheric processes in complex terrain at subkilometer resolutions [12]. Statistical downscaling techniques include regression techniques and stochastic modeling [13]. Many statistical downscaling techniques assume a constant lapse rate to downscale temperatures to spatial scales on the order of $20 \mathrm{~km}$ [14]. Assuming a constant lapse rate is not justified for many regions [15] because lapse rates exhibit significant spatial variability that are a function of season $[16,17]$, slope position (i.e., leeward versus windward) [15], and slope azimuth $[18,19]$.

On the other hand, gridded climate data sets at high resolution (on the scale of $1-4 \mathrm{~km}$ ) have been developed from which spatially and temporally varying lapse rates can be derived. Two widely known examples of these gridded climate data sets that are based on networks of surface observations are the Parameter-elevation Regression on Independent Slopes Model (PRISM) [20, 21] and the Daily Surface Weather and Climatological Summary (DAYMET) 
[22] which have been used in, for example, ecological applications [23] and climate studies [24].

To obtain accurate temperature projections at subkilometer scales, statistical downscaling methods could use the spatially and temporally varying lapse rates that can be derived from high-resolution gridded data sets. In this study, we develop such a downscaling method and use this method to downscale near-surface temperatures maps at the high elevation habitats of $P$. shenandoah in SNP under current and future climate conditions. We limit ourselves to a demonstration of our downscaling method for July maximum temperatures motivated by the importance of changes in summer maximum temperatures to the survival of $P$. shenandoah.

\section{Methods}

2.1. Site Description. SNP is located along the crest of the Virginia Blue Ridge Mountains on the eastern flank of the southern Appalachians in the eastern US. The park is oriented southwest-northeast and extends $115 \mathrm{~km}$ from near Waynesboro, Virginia, to Front Royal, Virginia. Elevations in SNP range from $200 \mathrm{~m}$ above mean sea level (msl) in the valleys to $1000-1200 \mathrm{~m} \mathrm{msl}$ along the ridgeline. East of SNP is the Virginia Piedmont, and the Shenandoah Valley is west of SNP. The climate of SNP ranges from humid subtropical at the lower elevations to humid continental along the ridgetops.

2.2. Downscaling Method. Our downscaling method uses the gridded temperature data sets from PRISM. PRISM assimilates observations of temperature (precipitation) from approximately 10,000 $(13,000)$ surface stations in the conterminous US and linearly interpolates these observations to high spatial resolutions using elevation, ocean proximity, and topographic facet [20,25]. PRISM outputs two data sets: (1) mean monthly maximum and minimum temperature and total precipitation from 1895 through 2013 at a $4 \mathrm{~km}$ resolution and (2) 30-year monthly climate means for maximum and minimum temperature and total precipitation averaged over 1971-2000 (and, as of 2014, 1981-2010) at $800 \mathrm{~m}$ spatial resolution [20, 21]. PRISM gridded data sets are available online from http://prism.oregonstate.edu/.

The $4 \mathrm{~km}$ and $800 \mathrm{~m}$ spatial resolutions of the PRISM data sets are too coarse to resolve temperature variability across the habitats of $P$. shenandoah, and thus further downscaling is required. In our downscaling method (Figure 1), we downscale the $4 \mathrm{~km}$ PRISM mean monthly maximum temperature to a $15 \mathrm{~m}$ resolution digital elevation model (DEM), which is the highest-resolution DEM available for the region, using spatially and temporally varying lapse rates. These lapse rates represent the line of best fit between elevation and the 30year, $800 \mathrm{~m}$ mean monthly maximum temperature for the 25 elevation-temperature pairs within each $4 \mathrm{~km}$ grid cell. Throughout SNP, this relationship is high $(r>0.98, P<$ 0.001 ). Thus, the downscaled maximum temperature can be written as follows:

$$
T_{\text {Downscaled }}=\overline{T_{4 \mathrm{~km}}}+\left(Z_{4 \mathrm{~km}}-Z_{\mathrm{DEM}}\right) \cdot \mathrm{LR}_{0.8 \mathrm{~km}},
$$

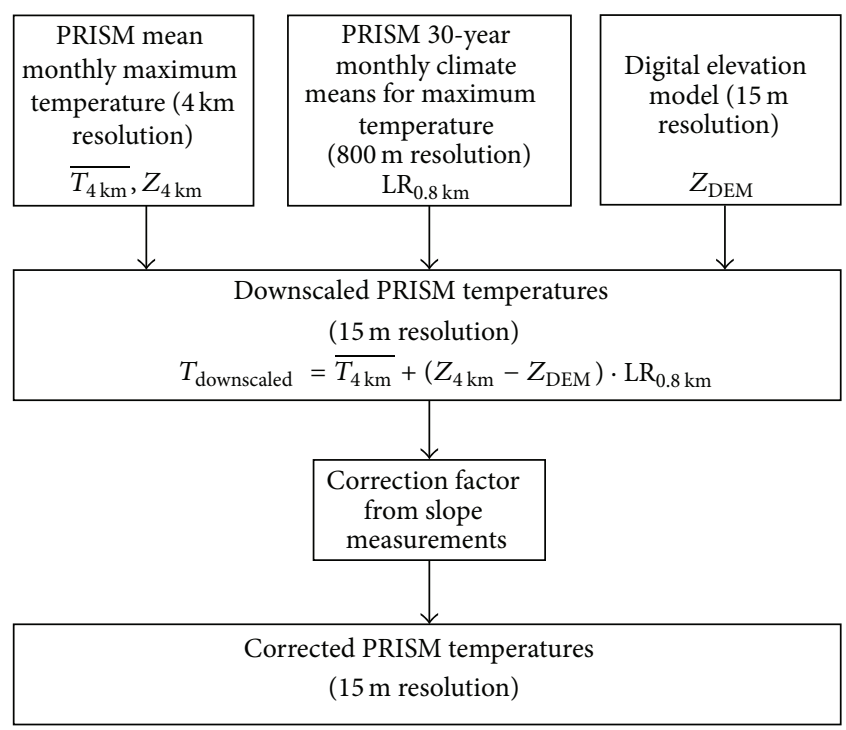

Figure 1: Summary of our downscaling method in which we downscale the monthly $4 \mathrm{~km}$ mean monthly maximum PRISM temperature $\left(\overline{T_{4 \mathrm{~km}}}\right)$ to a $15 \mathrm{~m}$ resolution DEM based on the lapse rates derived from the $800 \mathrm{~m}$ PRISM 30 -year monthly climate means for maximum temperature over the period 1971-2000 $\left(\mathrm{LR}_{0.8 \mathrm{~km}}\right)$ and the difference between the mean elevation of the $4 \mathrm{~km}$ grid box $\left(Z_{4 \mathrm{~km}}\right)$ and elevation of each $15 \mathrm{~m}$ grid cell $\left(Z_{\mathrm{DEM}}\right)$ to obtain downscaled PRISM ( $T_{\text {Downscaled }}$ ) at a $15 \mathrm{~m}$ resolution. We then apply a correction to $T_{\text {Downscaled }}$ based on the slope temperature measurements to obtain more realistic, high-resolution estimates of temperature in Shenandoah National Park.

where $T_{\text {Downscaled }}$ is the PRISM mean monthly maximum temperature downscaled to a $15 \mathrm{~m}$ resolution $\mathrm{DEM}, \overline{T_{4 \mathrm{~km}}}$ is the $4 \mathrm{~km}$ PRISM mean monthly maximum temperature, $Z_{4 \mathrm{~km}}$ is the mean elevation of the $4 \mathrm{~km}$ grid box, $Z_{\mathrm{DEM}}$ is the elevation of each $15 \mathrm{~m}$ grid cell, and $\mathrm{LR}_{0.8 \mathrm{~km}}$ is the lapse rate based on the $800 \mathrm{~m}$ PRISM 30-year monthly climate means for maximum temperature, where a positive lapse rate indicates a decrease in temperature with height. This downscaling method is evaluated using observations from a network of temperature sensors, discussed in the next section.

2.3. Slope Measurements. The observations which we use to evaluate our downscaling method come from a network of temperature sensors deployed in SNP. We use Onset HOBO Pro V2 temperature-relative humidity sensors which have a manufacturer-state accuracy of $\pm 0.21^{\circ} \mathrm{C}$ over the range $0^{\circ}$ to $50^{\circ} \mathrm{C}$ for temperature and $\pm 2.5 \%$ from $10 \%$ to $90 \%$ for relative humidity. These sensors have been tested and used successfully in many applications to investigate near-surface temperature variations $[26,27]$.

In April, 2011, we deployed 37 sensors along 3 transects in SNP. The transect east of the ridgeline included 18 sensors, and the transects west of the ridgeline included 19 sensors (Figure 2). For all transects, sensors were deployed along a line extending from near the ridgeline (about $1000 \mathrm{~m} \mathrm{msl}$ ) to about $600 \mathrm{~m}$ msl. Of the 19 sensors along the west side of the 


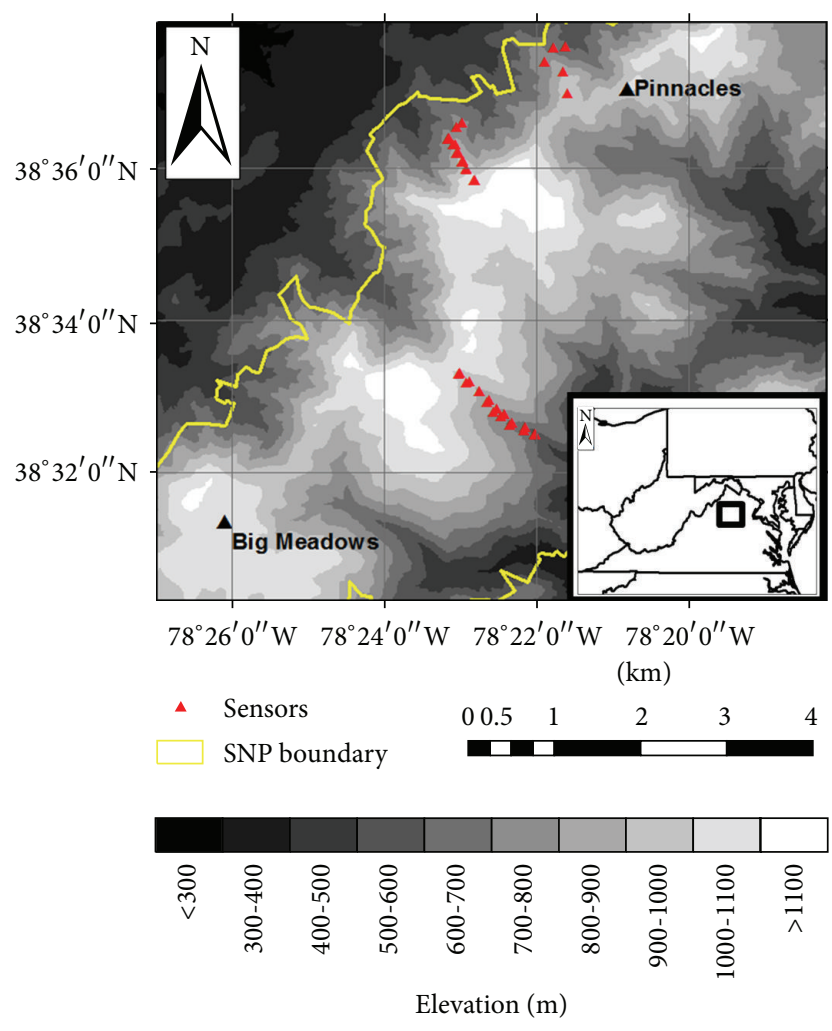

FIGURE 2: Location of experimental site within Virginia (black box in the inset map) and map of the study area. The red triangles and yellow line indicate the locations of the temperature sensors and the Shenandoah National Park boundary, respectively. The two ridgetop climate monitoring stations, Big Meadows and Pinnacles, are labeled and shown with a black triangle. Shading indicates elevation.

ridgeline, 14 were deployed along one transect and 5 were deployed along another transect $6 \mathrm{~km}$ to the north. Along the transect east of the ridgeline, we deployed sensors in pairs at nine different elevations to assess the impact of different slope azimuths on the temperature measurements. Sensors were deployed approximately $50 \mathrm{~m}$ apart at each elevation so that the effect of slope azimuth on temperature could be assessed.

We deployed all sensors adjacent to hiking trails for ease of access and to minimize disturbances to the area. They were attached to a fence post, installed $1.5 \mathrm{~m}$ above ground level (agl), and enclosed within a radiation shield (type RS3 from the Onset Corporation) to reduce radiation errors. All sensors were visited approximately every 2-3 months to download data. $60 \mathrm{~min}$ means from $10 \mathrm{~min}$ samples were computed, and the daily maximum temperature was determined from the 60 min means. The mean monthly $T_{\max }$ is the mean of all daily maximum temperatures during one month. Our analyses in this study are based on data collected between July 2011 and July 2013. The data set for this period is mostly complete, but there are occasional gaps in the record due to various factors such as water short-circuiting the sensor electronics, damage by wildlife, and difficulties downloading data from the sensor.
TABLE 1: Mean bias error between downscaled PRISM and the observations along the west and east slope of SNP in July 2011, 2012, and 2013.

\begin{tabular}{lcc}
\hline Month & West slope $\mathrm{MBE}\left({ }^{\circ} \mathrm{C}\right)$ & East slope $\mathrm{MBE}\left({ }^{\circ} \mathrm{C}\right)$ \\
\hline July, 2011 & 2.21 & 4.66 \\
July, 2012 & 1.91 & 3.50 \\
July, 2013 & 1.34 & 3.85 \\
\hline
\end{tabular}

2.4. Long-Term Climate Stations. In addition to evaluating our downscaling method using slope temperature measurements, we use $2 \mathrm{~m}$ air temperature data from two longterm monitoring sites along the ridgetop of SNP: Big Meadows $(38.53 \mathrm{~N}, 78.44 \mathrm{~W}, 1079 \mathrm{~m} \mathrm{msl})$ and Pinnacles $(38.62 \mathrm{~N}$, $78.35 \mathrm{~W}, 1017 \mathrm{~m} \mathrm{msl})$. The monitoring site at Big Meadows is located in an enclosed grassy field approximately $15 \mathrm{~m}$ from a mixed deciduous forest canopy. Observations of daily maximum and minimum temperature, as well as precipitation, began in 1935 and are obtained from the National Climate Data Center (NCDC). Hourly meteorological observations began in 1988 as part of the Environmental Protection Agency (EPA) Clean Air Status and Trends (CASTNET) network. Beginning in 2008, half hour meteorological measurements began at Pinnacles along a $17 \mathrm{~m}$ walkup tower located in a forest with a mean height of approximately $14 \mathrm{~m}$ [28]. Temperature data from a HOBO Pro V2 sensor installed $40 \mathrm{~m}$ north of the tower in a small grassy field at $1.5 \mathrm{~m}$ agl are also used.

2.5. Regional Climate Models. We apply our downscaling method to RCM output from the North American Regional Climate Change Assessment Program (NARCCAP). NARCCAP uses 4 GCMs that provide boundary conditions for 6 different RCMs [7, 8]. Because not all GCM-RCM combinations are available, we use output from 7 GCM-RCM combinations in this study. All GCM-RCM combinations that comprise NARCCAP have a $50 \times 50 \mathrm{~km}^{2}$ spatial resolution over North America and are run for the past (1971-2000) and future (2041-2070) using the Special Report on Emissions Scenarios (SRES) A2 emissions scenario [7]. The A2 scenario assumes rapid population growth and slow economic growth which result in greater anthropogenic $\mathrm{CO}_{2}$ emissions than in the other scenarios used by the Intergovernmental Panel on Climate Change (IPCC) [29].

\section{Results and Discussion}

3.1. Evaluation of the Downscaling Method. When we apply the downscaling method discussed in Section 2.2, we find that downscaled PRISM consistently overestimates mean monthly $T_{\max }$ in July 2011, 2012, and 2013 (Table 1). The largest overestimates occur along the east slope of SNP, where the mean bias error (MBE) between downscaled PRISM and the slope observations of mean $T_{\max }$ is $3.5-4.7^{\circ} \mathrm{C}$ (Figure 3). Along the west slope of SNP, the warm bias is smaller, but downscaled PRISM still overestimates mean July $T_{\max }$ by 1.3$2.2^{\circ} \mathrm{C}$. 


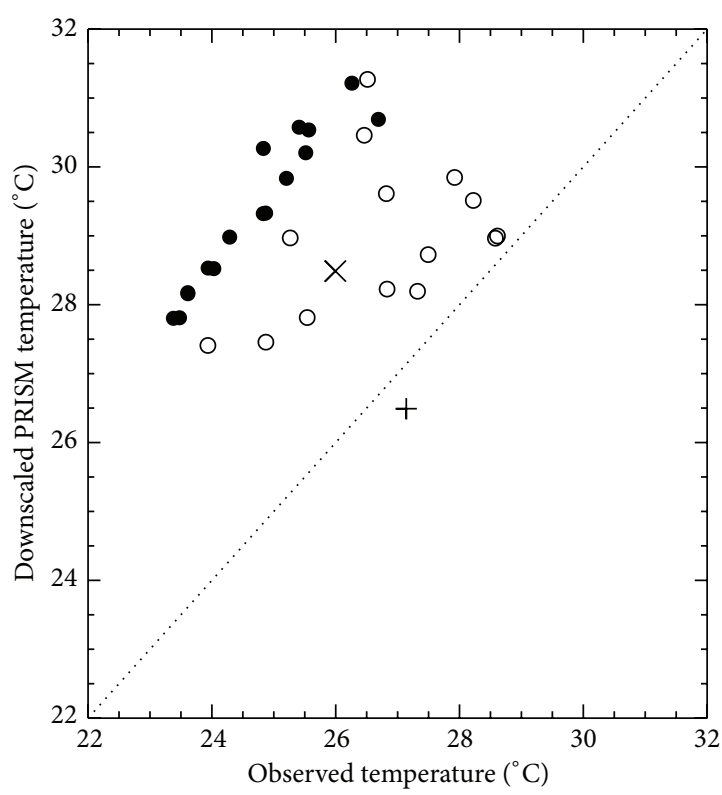

(a)

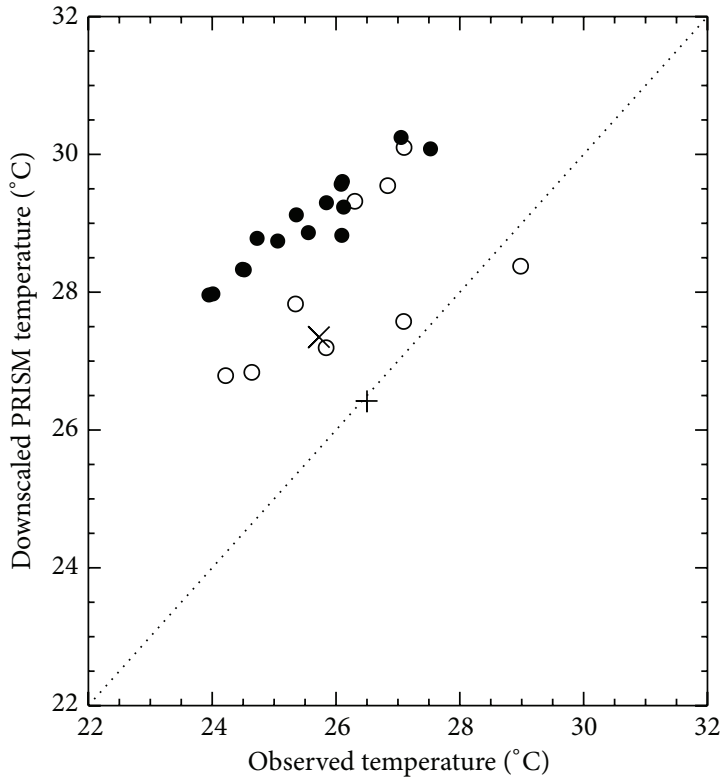

(b)

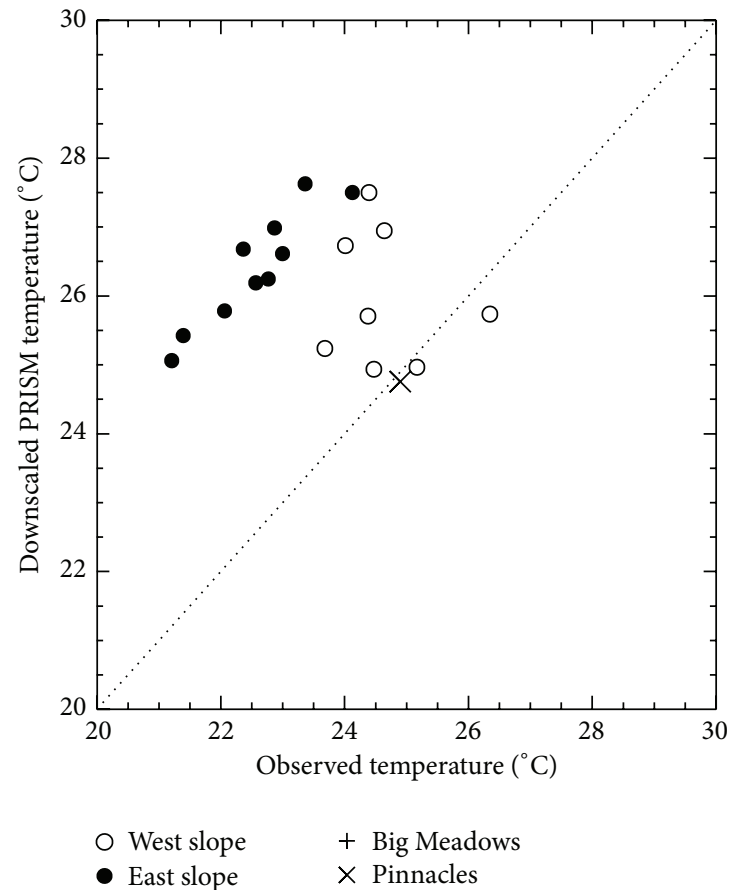

(c)

FIGURE 3: Comparison between observed mean July $T_{\max }$ from the sensor network and downscaled PRISM for July, 2011 (a), July, 2012 (b), and July, 2013 (c) using PRISM-derived lapse rates. Open circles indicate comparisons along the west slope; filled circles indicate comparisons along the east slope; "+" and "X" denote Big Meadows and Pinnacles, respectively. Black dotted line is the 1:1 line. Note that Big Meadows measurements are unavailable in 2013. Also note the same range but different scales on the $x$-axis and $y$-axis in panel (c).

There are also differences in mean July $T_{\max }$ between the sensor pairs deployed at different azimuths along the east slope, with mean July $T_{\max }$ along the southeast-facing slopes on average $0.5^{\circ} \mathrm{C}$ higher than the northeast-facing slopes. These differences are lower than those reported in previous studies by, for example, Bolstad et al. [19] in the Smoky Mountains, where mean daily $T_{\max }$ was $1.4^{\circ} \mathrm{C}$ higher along south-facing slopes than along northwest-facing slopes regardless of season. The larger differences in the Bolstad et al. study occur because neither of the slopes on which our 
TABLE 2: $4 \mathrm{~km}$ PRISM mean elevation, $4 \mathrm{~km}$ PRISM lapse rate based on $800 \mathrm{~m}$ PRISM climate means, and July 2011, 2012, and 2013 $4 \mathrm{~km}$ PRISM mean July $T_{\max }$ for the locations at which temperature sensors were deployed along the west slope and east slope of SNP.

\begin{tabular}{lcc}
\hline PRISM variable & West slope & East slope \\
\hline $4 \mathrm{~km}$ mean elevation from PRISM $(\mathrm{m})$ & 646.69 & 888.89 \\
$4 \mathrm{~km}$ PRISM lapse rate based on $800 \mathrm{~m}$ PRISM climate means $\left({ }^{\circ} \mathrm{C} \mathrm{km}^{-1}\right)$ & 7.84 & 7.80 \\
2011 mean July $T_{\max }$ from PRISM $\left({ }^{\circ} \mathrm{C}\right)$ & 30.87 & 28.72 \\
2012 mean July $T_{\max }$ from PRISM $\left({ }^{\circ} \mathrm{C}\right)$ & 30.08 & 28.19 \\
2013 mean July $T_{\max }$ from PRISM $\left({ }^{\circ} \mathrm{C}\right)$ & 27.46 & 25.61 \\
\hline
\end{tabular}

sensors were deployed was oriented either directly north or directly south and because the sensors in the Bolstad et al. study were installed above the forest canopy.

\subsection{Causes for Differences between Maximum Tempera-} tures from the Downscaling Method and Observations. The observed differences between mean July $T_{\max }$ from the measured slope temperatures and downscaled PRISM highlight some of the challenges that arise when using PRISM in mountainous regions. Differences can occur because of errors in PRISM and/or observational errors. The warm bias in downscaled PRISM can arise because of the interpolation of climatological data in data-sparse regions. PRISM interpolates data from climate stations by calculating a linear relationship (lapse rate in the case of temperature) between elevation and the variable of interest, which is linearly extrapolated in locations where there are no high-elevation stations $[21,25]$. Thus, in regions with nearby observation stations at similar elevations, PRISM performs well. At SNP Headquarters in Luray, VA (38.67 N, 78.37 W, $359 \mathrm{~m} \mathrm{msl),}$ which is the nearest low elevation station to SNP and is located about $5 \mathrm{~km}$ northwest of the transect of sensors along the west slope, downscaled PRISM and observed mean July $T_{\max }$ agree to within about $0.5^{\circ} \mathrm{C}$. The warm bias in downscaled PRISM may occur because the mean monthly $4 \mathrm{~km}$ PRISM July $T_{\max }$ grids are based on temperatures made at relatively low elevation stations. We note that the lapse rates of $7-8^{\circ} \mathrm{C} \mathrm{km}^{-1}$ based on the 30 -year climate means (Table 2) are comparable to the mean July $T_{\max }$ lapse rates observed along the slope. The overestimates in the $4 \mathrm{~km}$ July $T_{\max }$ PRISM grids are most evident in July 2011 and July 2012 when the largest warm bias exists. In July 2013 when the $4 \mathrm{~km}$ July $T_{\max }$ is about $3^{\circ} \mathrm{C}$ lower, there is better agreement along the west slope but slightly worse agreement along the east slope. We suspect that the warm bias in downscaled PRISM is partly caused by the lack of high elevation stations in the region that can help constrain temperature estimates along the slopes of SNP.

A warm bias in downscaled PRISM may also occur because of canopy cover differences between the low elevation sites (used in PRISM) and the mountain slopes of SNP. All of the locations along the slopes at which we deployed temperature sensors have canopy cover $>60 \%$ based on ArcGIS analyses and on our own observations. Deployment in locations with dense canopies helped to minimize radiation errors that can occur in the naturally ventilated radiation shields used in this study [30]. However, many of the climate stations used in PRISM are not located in forests but instead located in grassy fields, which typically have higher daytime maximum temperatures [31, 32]. At Pinnacles, mean July $T_{\max }$ measured $2 \mathrm{~m}$ agl within the forest canopy is on average $2^{\circ} \mathrm{C}$ cooler than the temperature in the open, grassy field $40 \mathrm{~m}$ from the tower. Because of this difference, the July $T_{\max } \mathrm{MBE}$ is much smaller between downscaled PRISM and the measurements from the grassy field at Pinnacles than between downscaled PRISM and the measurements from within the forest canopy at Pinnacles. Similarly, downscaled PRISM agrees well with temperature observations from Big Meadows (c.f. Figure 3), which is a monitoring station more typical of the stations used to generate the PRISM data sets.

Differences in slope azimuth angle may also explain some of the bias between downscaled PRISM and the observations. The west slope has greater afternoon exposure and thus higher average near-surface incoming solar radiation [33] than the east slope, resulting in higher mean monthly $T_{\max }$ than the east slope and thus better agreement with downscaled PRISM.

Thus, we conclude that the warm bias in downscaled PRISM is due to a combination of factors, including a lack of high elevation stations in the region to constrain temperature estimates along the slopes of SNP, and differences in canopy cover and slope azimuth. To further investigate the potential effect of canopy cover and slope azimuth, we apply our downscaling method to January when these factors exert a smaller influence on temperature. In January, the overestimates in downscaled PRISM temperature are smaller than in July, on the order of $1.0-1.5^{\circ} \mathrm{C}$, and the biases along the eastern and western slope are comparable to each other. Furthermore, the differences in mean January $T_{\max }$ between the sensor $1.5 \mathrm{~m}$ agl along the tower at Pinnacles and the sensor in the adjacent field are negligible and are within the manufacturer's stated accuracy of the sensors. Because downscaled PRISM agrees better with the observations in the winter when the effects of canopy cover and azimuth are reduced, we suspect that PRISM's warm bias in mean July $T_{\max }$ along the slopes in SNP occurs because (1) the stations used to generate the monthly $4 \mathrm{~km}$ PRISM grids in and around SNP are located at low elevation, nonforested sites and (2) there is a lack of surface monitoring stations at high elevations to constrain temperature estimates.

3.3. Corrections to Downscaled PRISM for SNP. To summarize, the monthly $4 \mathrm{~km}$ PRISM mean July $T_{\max }$ (Figure $4(\mathrm{a})$ ) does not account for the fine-scale temperature variations at 


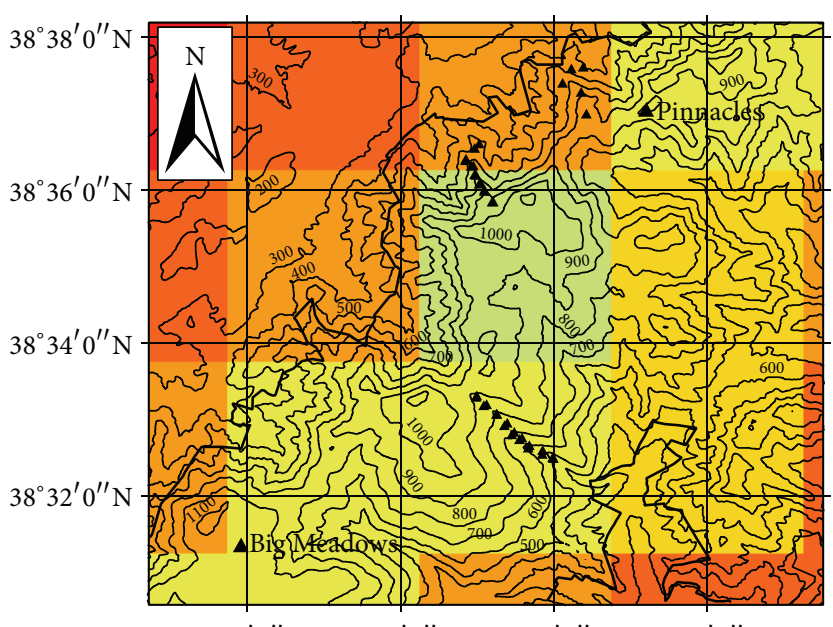

$78^{\circ} 26^{\prime} 0^{\prime \prime} \mathrm{W} \quad 78^{\circ} 24^{\prime} 0^{\prime \prime} \mathrm{W} \quad 78^{\circ} 22^{\prime} 0^{\prime \prime} \mathrm{W} \quad 78^{\circ} 20^{\prime} 0^{\prime \prime} \mathrm{W}$

(a)

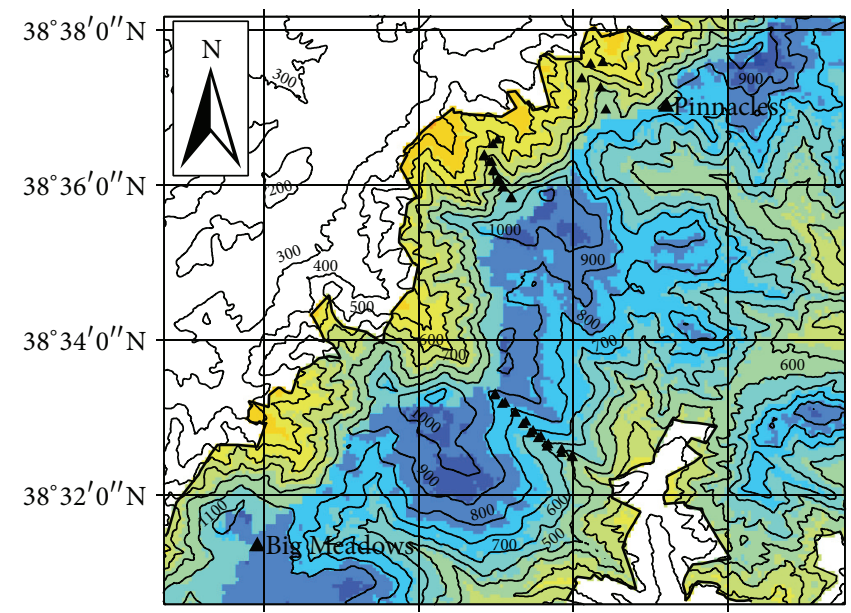

$78^{\circ} 26^{\prime} 0^{\prime \prime} \mathrm{W} \quad 78^{\circ} 24^{\prime} 0^{\prime \prime} \mathrm{W} \quad 78^{\circ} 22^{\prime} 0^{\prime \prime} \mathrm{W} \quad 78^{\circ} 20^{\prime} 0^{\prime \prime} \mathrm{W}$

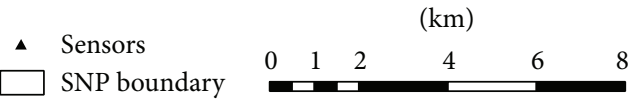

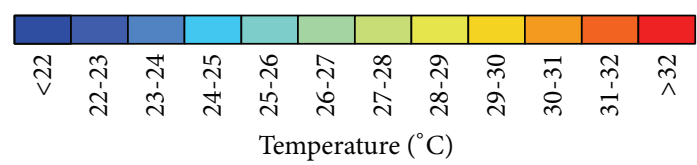

(c)

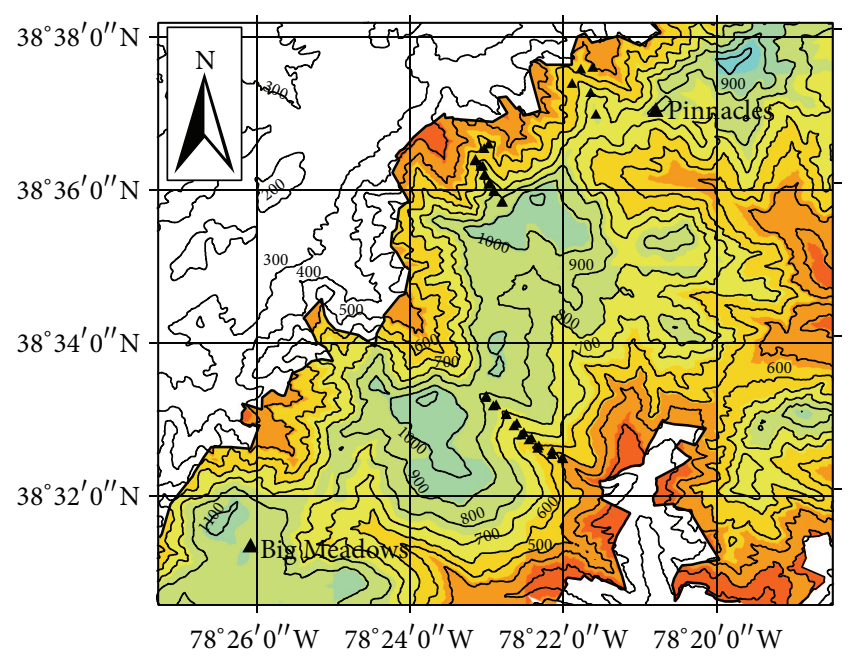

(b)

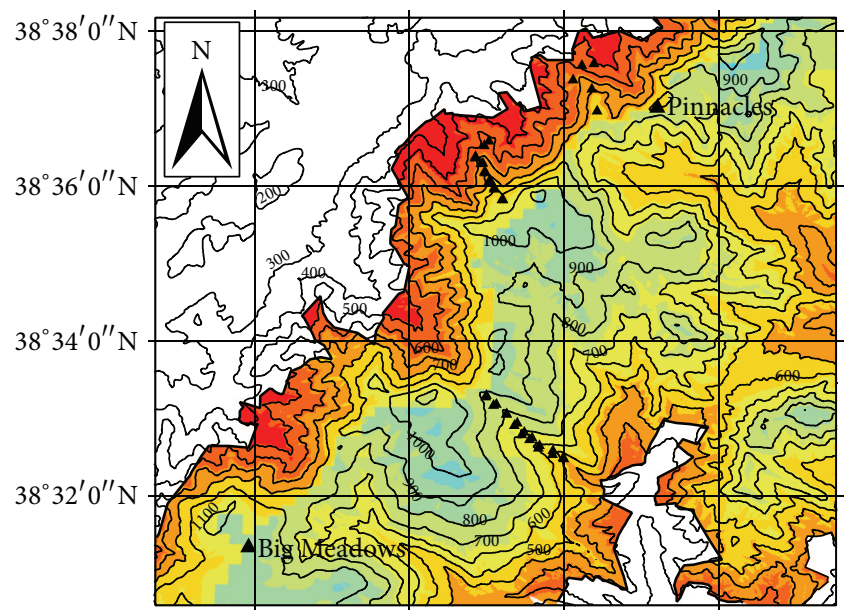

$78^{\circ} 26^{\prime} 0^{\prime \prime} \mathrm{W} \quad 78^{\circ} 24^{\prime} 0^{\prime \prime} \mathrm{W} \quad 78^{\circ} 22^{\prime} 0^{\prime \prime} \mathrm{W} \quad 78^{\circ} 20^{\prime} 0^{\prime \prime} \mathrm{W}$

$(\mathrm{km})$

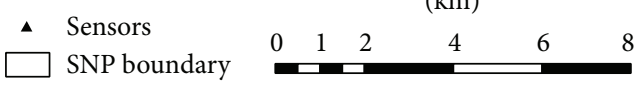

\begin{tabular}{|c|c|c|c|c|c|c|c|c|c|c|c|}
\hline & & & & & & & & & & & 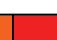 \\
\hline$\tilde{N}$ & $\ddot{\sim}$ & 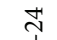 & $\stackrel{\stackrel{2}{\sim}}{\sim}$ & డి & $\widehat{\curvearrowright}$ & $\stackrel{\sim}{\sim}$ & ণิ & 요 & $\vec{m}$ & 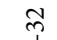 & $\pi$ \\
\hline & त่ & $\ddot{\sim}$ & $\stackrel{\dot{H}}{\sim}$ & $\stackrel{\stackrel{\leftrightarrow}{\sim}}{ }$ & 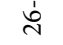 & ત̀ & $\stackrel{\infty}{\sim}$ & ঐे & dे & $\frac{1}{m}$ & \\
\hline & & & & $\mathrm{Tem}$ & npera & ature & $\left({ }^{\circ} \mathrm{C}\right)$ & & & & \\
\hline
\end{tabular}

(d)

FIGURE 4: Maps of mean $T_{\max }$ for July 2012 resulting from the different steps in our downscaling method. Panel (a) shows 4 km PRISM output; panel (b) shows PRISM downscaled to $15 \mathrm{~m}$ in SNP using the 30-year PRISM lapse rates and without any corrections applied; panel (c) shows PRISM downscaled to $15 \mathrm{~m}$ in SNP with our corrections from Table 1 applied to each $15 \mathrm{~m}$ grid box; panel (d) shows estimated mean $T_{\max }$ in SNP assuming a temperature increase of $3.3^{\circ} \mathrm{C}$ (average projected temperature increase from NARCCAP RCMs for SNP) applied to July, 2012 mean $T_{\max }$. Thin black lines denote elevation contours at $100 \mathrm{~m}$ spacing, with contour lines labeled; solid black line indicates the SNP boundary; black triangles mark temperature sensors; and the two ridgetop climate monitoring stations, Big Meadows and Pinnacles, are labeled. Note that the downscaling method is only applied to a $15 \mathrm{~m}$ DEM inside the SNP boundary (panels (b)-(d)).

high elevation habitats in the region. Downscaling using lapse rates based on the 30-year climate means (Figure $4(\mathrm{~b})$ ) yields temperature estimates that have a warm bias and thus do not agree well with the observations. Therefore, we introduce corrections to the downscaled PRISM to provide more accurate estimates of present-day mean monthly $T_{\max }$ in SNP. The corrections that we apply are a function of (1) location relative to the ridgeline, which we define using catchment delineation in ArcGIS, and (2) slope azimuth obtained from a $15 \mathrm{~m}$ DEM. The corrections are thus the MBE between the 
TABLE 3: Summary of empirical corrections applied to downscaled PRISM mean July $T_{\max }$.

\begin{tabular}{lcc}
\hline & $\begin{array}{c}\text { Correction applied to downscaled PRISM } \\
\text { mean July } T_{\max } \text { along south-facing slopes } \\
\left({ }^{\circ} \mathrm{C}\right)\end{array}$ & $\begin{array}{c}\text { Correction applied to downscaled PRISM } \\
\text { mean July } T_{\text {max }} \text { along non-south-facing } \\
\text { slopes }\left({ }^{\circ} \mathrm{C}\right)\end{array}$ \\
\hline West slope in SNP & 1.32 & 1.82 \\
East slope in SNP & 3.50 & 4.00 \\
\hline
\end{tabular}

observations and downscaled PRISM averaged over July, 2011, July 2012, and July, 2013 (Table 3). Therefore, locations west (east) of the ridgeline and locations that are south-facing (not south-facing) have a smaller (larger) correction. The use of these corrections enables us to produce high-resolution maps of present-day mean monthly $T_{\max }$ in SNP (Figure 4(c)) that are more accurate than the maps shown in Figures 4(a) and $4(b)$.

3.4. Climate Change Projections for SNP Using RCMs. The corrected fine-scale present-day maps of mean monthly $T_{\max }$ from Figure 4(c) can be used to estimate future temperatures in the habitat of P. shenandoah and in SNP using a temperature change obtained from the NARCCAP RCMs. To provide confidence in the NARCCAP RCMs, we compare observed monthly $T_{\max }$ from the Big Meadows NCDC data set with NARCCAP output over the period 1971-2000. Due to the coarse resolution of the NARCCAP RCMs, the elevation of the NARCCAP grid box containing Big Meadows is about $800 \mathrm{~m}$ lower than Big Meadows' actual elevation. Thus, all NARCCAP RCMs overestimate the temperature at Big Meadows. The GFDL-RCM3 model has the smallest MBE, whereas the CRCM-CCSM model has the largest MBE.

All models project an increase in mean July $T_{\max }$ of 2$4^{\circ} \mathrm{C}\left(0.3-0.6^{\circ} \mathrm{C}\right.$ decade $\left.^{-1}\right)$ through 2055 for the grid box containing the P. shenandoah habitat and Big Meadows. The CGCM-WRFG (GFDL-HRM3) model suggests the smallest (largest) increase $\left(0.29^{\circ} \mathrm{C}\right.$ decade $\left.^{-1}\right)\left(+0.60^{\circ} \mathrm{C}\right.$ decade $\left.^{-1}\right)$, whereas the GFDL-RCM3 model projects an increase of $0.44^{\circ} \mathrm{C}$ decade $^{-1}$ (Table 4 ).

To estimate the projected changes in mean July $T_{\max }$ between the present-day and future NARCCAP simulations, we apply the mean temperature increase in NARCCAP RCMs $\left(3.3^{\circ} \mathrm{C}\right)$ to present-day mean July $T_{\max }$ (Figure $4(\mathrm{~d})$ ). These types of maps can be used by biologists and resource managers to assess and mitigate the effects of climate change on habitats such as those of P. shenandoah.

3.5. Application of the Downscaling Method to other Gridded Climate Data Sets. While we have focused on using PRISM in our downscaling method, other gridded climate data sets could be used as well. One example is DAYMET. DAYMET uses a weighted least-squares regression to interpolate temperature, precipitation, moisture, and radiation measurements from about 8000 surface monitoring stations to a $1 \mathrm{~km}$ resolution over the conterminous US [22]. When we use DAYMET in our downscaling method for mean monthly $T_{\max }$, we find a bias similar to PRISM. Whereas downscaled
TABLE 4: Projected change in mean July $T_{\max }$ in SNP. Shown in parentheses is the projected change in mean July $T_{\max }$ in ${ }^{\circ} \mathrm{C}$ decade $^{-1}$. The full names of the GCM-RCM combinations are CCSM-CRCM: community climate system model-Canadian regional climate model; CGCM-CRCM: coupled general circulation model-Canadian regional climate model; CCSM-WRFG: community climate system model-weather research and forecasting model; CGCM-WRFG: coupled general circulation model-weather research and forecasting model; GFDL-HRM3: geophysical fluid dynamics model-Hadley regional model version 3; CGCM-RCM3, Coupled General Circulation model-regional climate model version 3; GFDL-HRM3: geophysical fluid dynamics model-Hadley regional model version 3 .

\begin{tabular}{lc}
\hline GCM-RCM & $\begin{array}{c}\text { Change in mean July } T_{\max }\left({ }^{\circ} \mathrm{C}\right)\left({ }^{\circ} \mathrm{C}\right. \\
\left.\text { decade }^{-1}\right)\end{array}$ \\
\hline CCSM-CRCM & $+3.37(+0.48)$ \\
CGCM-CRCM & $+3.91(+0.56)$ \\
CCSM-WRFG & $+3.44(+0.49)$ \\
CGCM-WRFG & $+2.04(+0.29)$ \\
GFDL-HRM3 & $+4.23(+0.60)$ \\
CGCM-RCM3 & $+2.74(+0.39)$ \\
GFDL-RCM3 & $+3.11(+0.44)$ \\
\hline
\end{tabular}

mean monthly $T_{\max }$ using DAYMET and PRISM correlate well $(r=0.85, P<0.01)$, downscaled mean monthly $T_{\max }$ using DAYMET also overestimates temperatures along both the west slope and east slope, with a bias in mean July $T_{\max }$ of about $4^{\circ} \mathrm{C}\left(6^{\circ} \mathrm{C}\right)$ along the west (east) slope and a $1-2^{\circ} \mathrm{C}$ bias in winter. Thus, the use of DAYMET for mean July $T_{\max }$ is also unreliable in SNP without using corrections.

3.6. Limitations of the Downscaling Method. The downscaling method presented in this paper is an important step toward making gridded climate data sets such as PRISM or DAYMET more reliable in regions of complex terrain. However, there are some limitations and caveats that are not explicitly considered with our downscaling method.

(1) Our downscaling method does not consider yearto-year lapse rate variations but instead downscales, assuming a lapse rate based on 30-year climate means. Although mean maximum temperatures were about $2-3^{\circ} \mathrm{C}$ higher in July 2011 than in July 2013 at the sites where temperature was measured in SNP, the lapse rates showed relatively little variability in the three July months of interest and compared well with the 30-year mean PRISM lapse rates. 
(2) Our downscaling method does not explicitly incorporate other factors that affect near-surface temperature on subkilometer spatial scales, such as vegetation cover, soil moisture, soil type, vegetation type [26, 34], and shading by adjacent mountain ridges [33]. Further understanding and explicitly quantifying these effects and their relative importance over the spatial scale of SNP is very difficult and requires extensive networks of high-density observations. In addition, high-resolution atmospheric model simulations could be used to help isolate some of the other important drivers of near-surface spatiotemporal temperature variability in this region.

In addition to limitations with the downscaling method itself, there are several limitations with the corrections that we introduce in this study to make PRISM more reliable in SNP.

(1) The corrections do not vary with elevation. We found that the difference between observed and downscaled mean July $T_{\max }$ for the sensors deployed along the east slope did not vary as a function of elevation. Along the west slope of SNP, there was more variability in this temperature difference because of greater variability in local slope characteristics that affect temperature, for example, inclination and azimuth $[18,19,26]$, than along the east slope.

(2) There is a discontinuity in downscaled temperature present along the ridgeline. To remove this discontinuity, the application of our correction should decrease with elevation in the immediate vicinity of the ridgeline. Due to logistical constraints such as the accessibility to some areas, permission issues, and manpower requirements, each transect does not begin right at the ridgeline. Therefore, we cannot fully assess the necessary corrections that should be applied within forested locations near the ridgeline.

(3) Because of the logistical constraints mentioned previously, our corrections for slope azimuth are not based on measurements made along slopes that were either directly north-facing or directly south-facing. Instead, our correction for azimuth is based on measurements from northeast-facing and southeastfacing slopes. Based on previous studies [19], we expect a larger temperature difference between slopes that are truly north-facing and slopes that are truly south-facing.

(4) The correction factors are based on data from three July months. Although data from more July months would help to refine the empirical correction factors that we apply to PRISM, we expect that, even with additional years of data, these correction factors will change by no more than about $0.5^{\circ} \mathrm{C}$, which is much smaller than the range of projected temperature changes from the suite of NARCCAP RCMs (c.f. Table 4).

\section{Conclusions and Implications}

In this study, we have presented a new method to downscale maximum temperatures in a mountainous region using PRISM and have evaluated our method with temperature observations from mountain slopes in SNP. We found that the downscaled maximum temperatures using PRISM, as well as using other gridded climate data sets, have a warm bias in SNP. Several reasons for this warm bias were suggested, including the lack of high-elevation stations in the region to constrain temperature estimates and the effects of canopy cover and slope azimuth. To reduce the warm bias, we introduced corrections that depend on the location relative to the ridgeline and the location's azimuth. Including corrections in the downscaling method provides more accurate estimates of near-surface temperature than could be obtained using either a fixed environmental lapse rate or a spatially varying lapse rate based on 30-year PRISM climate means. Though there are several limitations, the application of our corrections to downscaled PRISM represents an important step to improve temperature projections at subkilometer spatial scales in SNP and potentially in other mountainous areas as well. Therefore, future work should involve the testing and application of our downscaling method to other mountain slopes. Ongoing and future work also involves using high-resolution atmospheric mesoscale models to dynamically downscale RCM output to SNP and to evaluate how dynamical downscaling methods compare with the method presented here.

\section{Conflict of Interests}

The authors declare that there is no conflict of interests regarding the publication of this paper.

\section{Acknowledgments}

This research and maintenance of the temperature sensor network was funded by the National Park Service Climate Change Response Program, Cooperative Agreement 484010004. Support for student assistantships that helped maintain and analyze data from this network was also provided by NSF-CAREER Grant ATM-1151445. The authors thank Evan Grant and Adrianne Brand from the US Geological Survey for insightful discussions and feedback on the design of this study. They also thank students at the Department of Environmental Sciences at the University of Virginia for helping to maintain data collection from the sensor network, especially Stephanie Phelps and Mark Sghiatti. Thanks also to Željko Večenaj from the University of Zagreb, Croatia, for on-site support in 2012.

\section{References}

[1] IPCC, "Climate change 2007: The physical science basis," in Contribution of Working Group I to the Fourth Assessment Report of the Intergovernmental Panel on Climate Change, S. Solomon, D. Qin, M. Manning et al., Eds., pp. 1-996, Cambridge University Press, Cambridge, UK, 2007. 
[2] F. Giorgi, J. W. Hurrell, M. R. Marinucci, and M. Beniston, "Elevation dependency of the surface climate change signal: a model study," Journal of Climate, vol. 10, no. 2, pp. 288-296, 1997.

[3] R. S. Bradley, M. Vuille, H. F. Diaz, and W. Vergara, "Threats to water supplies in the tropical andes," Science, vol. 312, no. 5781, pp. 1755-1756, 2006.

[4] E. A. Beever, P. F. Brussard, and J. Berger, "Patterns of apparent extirpation among isolated populations of pikas (Ochotona princeps) in the Great Basin," Journal of Mammalogy, vol. 84, no. 1, pp. 37-54, 2003.

[5] N. L. Rodenhouse, S. N. Matthews, K. P. McFarland et al., "Potential effects of climate change on birds of the Northeast," Mitigation and Adaptation Strategies for Global Change, vol. 13, no. 5-6, pp. 517-540, 2008.

[6] R. Highton and R. D. Worthington, "A new salamander of the genus Plethodon from Virginia," Copeia, vol. 1967, no. 3, pp. 617626, 1967.

[7] L. O. Mearns, W. Gutowski, R. Jones et al., "A regional climate change assessment program for North America," Eos, Transactions American Geophysical Union, vol. 90, no. 36, pp. 311-313, 2009.

[8] L. O. Mearns, R. Arritt, S. Biner et al., "The north american regional climate change assessment program overview of phase i results," Bulletin of the American Meteorological Society, vol. 93, no. 9, pp. 1337-1362, 2012.

[9] M. Beniston, H. F. Diaz, and R. S. Bradley, "Climatic change at high elevation sites: an overview," Climatic Change, vol. 36, no. 3-4, pp. 233-251, 1997.

[10] S. Antic, R. Laprise, B. Denis, and R. de Elía, "Testing the downscaling ability of a one-way nested regional climate model in regions of complex topography," Climate Dynamics, vol. 26, no. 2-3, pp. 305-325, 2006.

[11] N. Salzmann, J. Nötzli, C. Hauck, S. Gruber, M. Hoelzle, and W. Haeberli, "Ground surface temperature scenarios in complex high-mountain topography based on regional climate model results," Journal of Geophysical Research F: Earth Surface, vol. 112, no. 2, Article ID F02S12, 2007.

[12] S. Zong and F. K. Chow, "Meso- and fine-scale modeling over complex terrain: parameterizations and applications," in Mountain Weather Research and Forecasting Recent Progress and Current Challenges, F. K. Chow, S. F. J. de Wekker, and B. J. Synder, Eds., pp. 591-653, Springer, New York, NY, USA, 2013.

[13] R. L. Wilby and T. M. L. Wigley, "Downscaling general circulation model output: a review of methods and limitations," Progress in Physical Geography, vol. 21, no. 4, pp. 530-548, 1997.

[14] R. Bordoy and P. Burlando, "Bias correction of regional climate model simulations in a region of complex orography," Journal of Applied Meteorology and Climatology, vol. 52, no. 1, pp. 82-101, 2013.

[15] J. R. Minder, P. W. Mote, and J. D. Lundquist, "Surface temperature lapse rates over complex terrain: lessons from the Cascade Mountains," Journal of Geophysical Research, vol. 115, Article ID D14122, 2010.

[16] C. Rolland, "Spatial and seasonal variations of air temperature lapse rates in alpine regions," Journal of Climate, vol. 16, pp. 1032-1046, 2003.

[17] T. R. Blandford, K. S. Humes, B. J. Harshburger, B. C. Moore, V. P. Walden, and H. Ye, "Seasonal and synoptic variations in nearsurface air temperature lapse rates in a mountainous basin," Journal of Applied Meteorology and Climatology, vol. 47, no. 1, pp. 249-261, 2008.
[18] Z. Tang and J. Fang, "Temperature variation along the northern and southern slopes of Mt. Taibai, China," Agricultural and Forest Meteorology, vol. 139, no. 3-4, pp. 200-207, 2006.

[19] P. V. Bolstad, L. Swift, F. Collins, and J. Régnière, "Measured and predicted air temperatures at basin to regional scales in the southern Appalachian mountains," Agricultural and Forest Meteorology, vol. 91, no. 3-4, pp. 161-176, 1998.

[20] C. Daly, G. H. Taylor, W. P. Gibson, T. W. Parzybok, G. L. Johnson, and P. A. Pasteris, "High-quality spatial climate data sets for the United States and beyond," Transactions of the American Society of Agricultural Engineers, vol. 43, no. 6, pp. 1957-1962, 2000.

[21] C. Daly, W. P. Gibson, G. H. Taylor, G. L. Johnson, and P. Pasteris, "A knowledge-based approach to the statistical mapping of climate," Climate Research, vol. 22, no. 2, pp. 99-113, 2002.

[22] P. E. Thornton, S. W. Running, and M. A. White, "Generating surfaces of daily meteorological variables over large regions of complex terrain," Journal of Hydrology, vol. 190, no. 3-4, pp. 214251, 1997.

[23] J. T. Abatzoglou, "Development of gridded surface meteorological data for ecological applications and modelling," International Journal of Climatology, vol. 33, no. 1, pp. 121-131, 2013.

[24] J. L. Weiss, C. L. Castro, and J. T. Overpeck, "Distinguishing pronounced droughts in the southwestern united states: seasonality and effects of warmer temperatures," Journal of Climate, vol. 22, no. 22, pp. 5918-5932, 2009.

[25] C. Daly, M. Halbleib, J. I. Smith et al., "Physiographically sensitive mapping of climatological temperature and precipitation across the conterminous United States," International Journal of Climatology, vol. 28, no. 15, pp. 2031-2064, 2008.

[26] J. D. Fridley, "Downscaling climate over complex terrain: High finescale $(<1000 \mathrm{~m})$ spatial variation of near-ground temperatures in a montane forested landscape (Great Smoky Mountains)," Journal of Applied Meteorology and Climatology, vol. 48, no. 5, pp. 1033-1049, 2009.

[27] C. D. Whiteman, J. M. Hubbe, and W. J. Shaw, "Evaluation of an inexpensive temperature datalogger for meteorological applications," Journal of Atmospheric and Oceanic Technology, vol. 17, no. 1, pp. 77-81, 2000.

[28] T. R. Lee, S. F. J. de Wekker, A. E. Andrews, J. Kofler, and J. Williams, "Carbon dioxide variability during cold front passages and fair weather days at a forested mountaintop site," Atmospheric Environment, vol. 46, pp. 405-416, 2012.

[29] N. Nakicenovic and R. Swart, Special Report on Emissions Scenarios: A Special Report of Working Group III of the Intergovernmental Panel on Climate Change, Cambridge University Press, Cambridge, UK, 2000.

[30] R. Nakamura and L. Mahrt, "Air temperature measurement errors in naturally ventilated radiation shields," Journal of Atmospheric and Oceanic Technology, vol. 22, no. 7, pp. 10461058, 2005.

[31] R. Geiger, The Climate Near the Ground, Harvard University Press, Cambridge, Mass, USA, 1965.

[32] M. D. Morecroft, M. E. Taylor, and H. R. Oliver, "Air and soil microclimates of deciduous woodland compared to an open site," Agricultural and Forest Meteorology, vol. 90, no. 1-2, pp. 141-156, 1998.

[33] C. D. Whiteman, Mountain Meteorology: Fundamentals and Applications, Oxford University Press, 2000.

[34] T. R. Oke, Boundary Layer Climates, Halsted Press, New York, NY, USA, 2nd edition, 1988. 

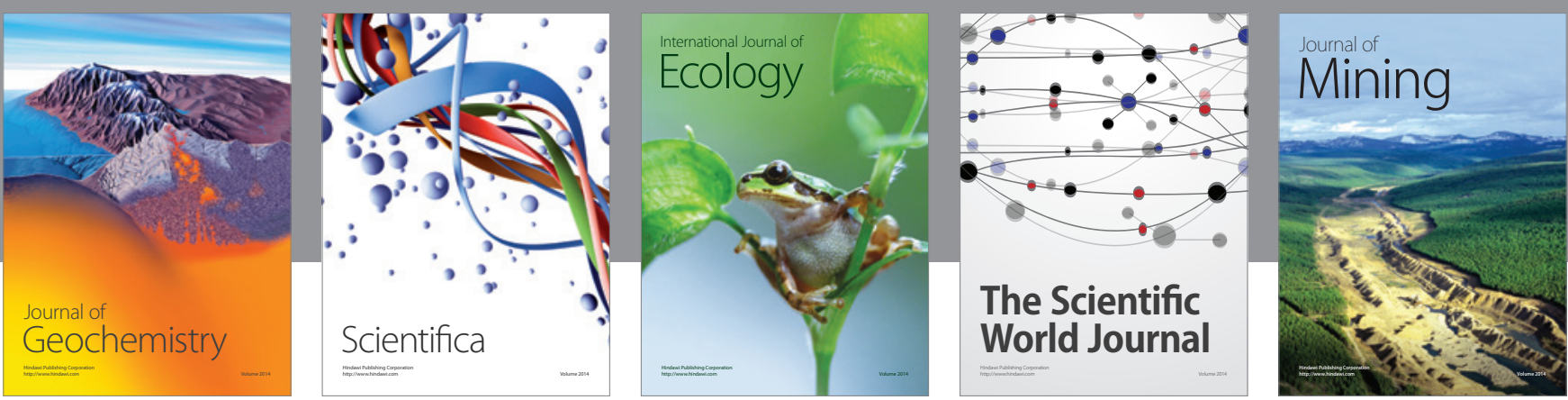

The Scientific World Journal
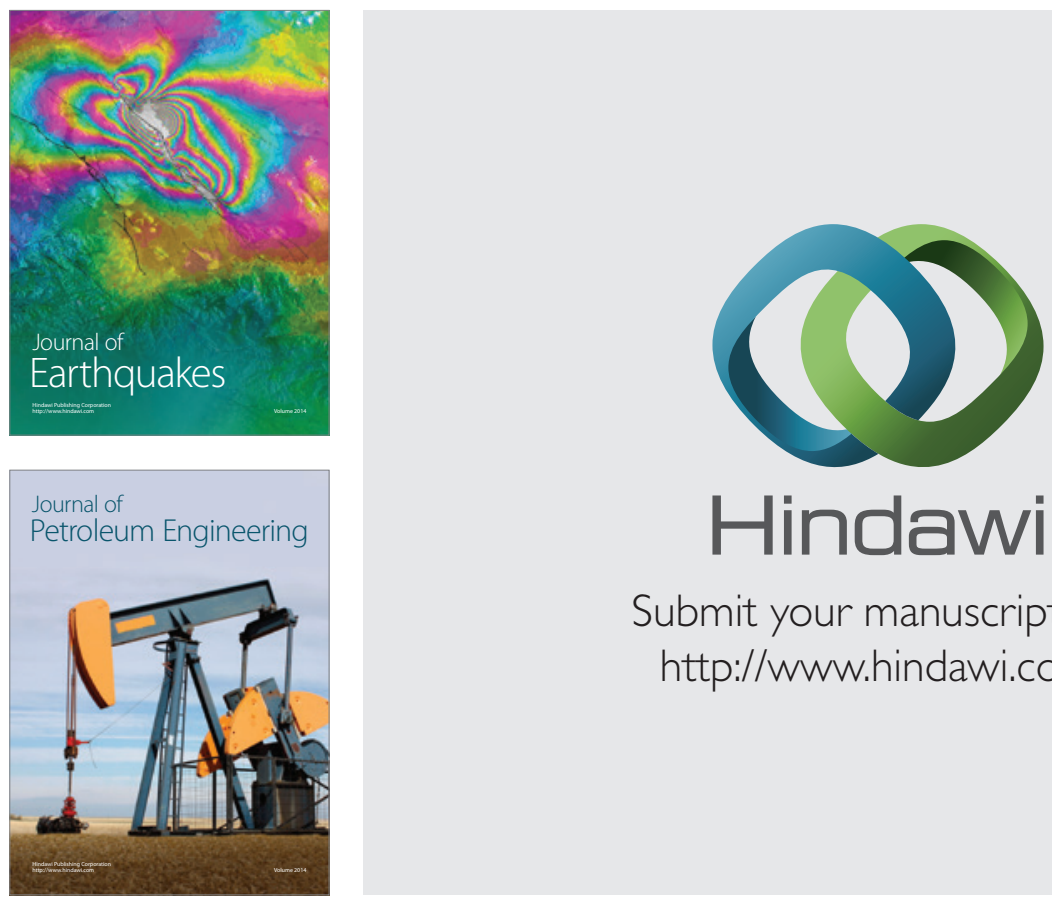

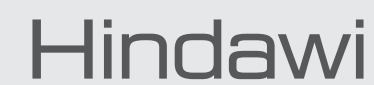

Submit your manuscripts at

http://www.hindawi.com
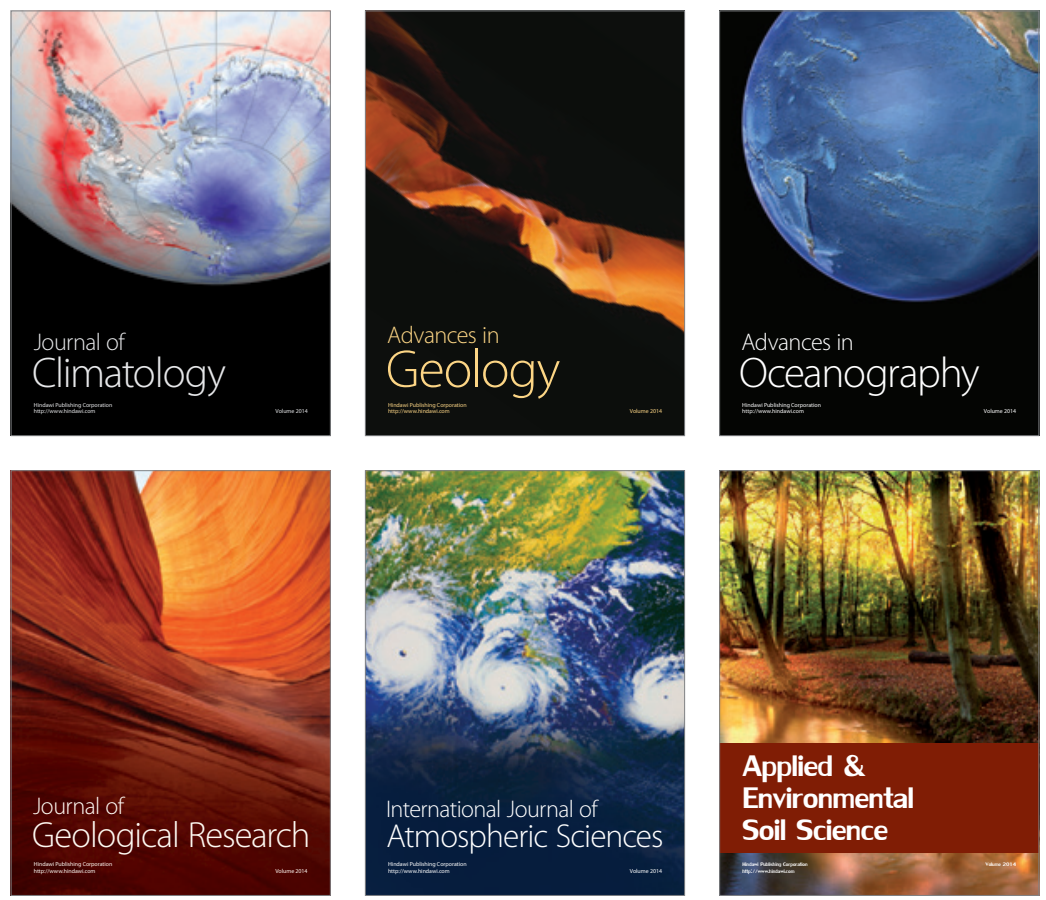
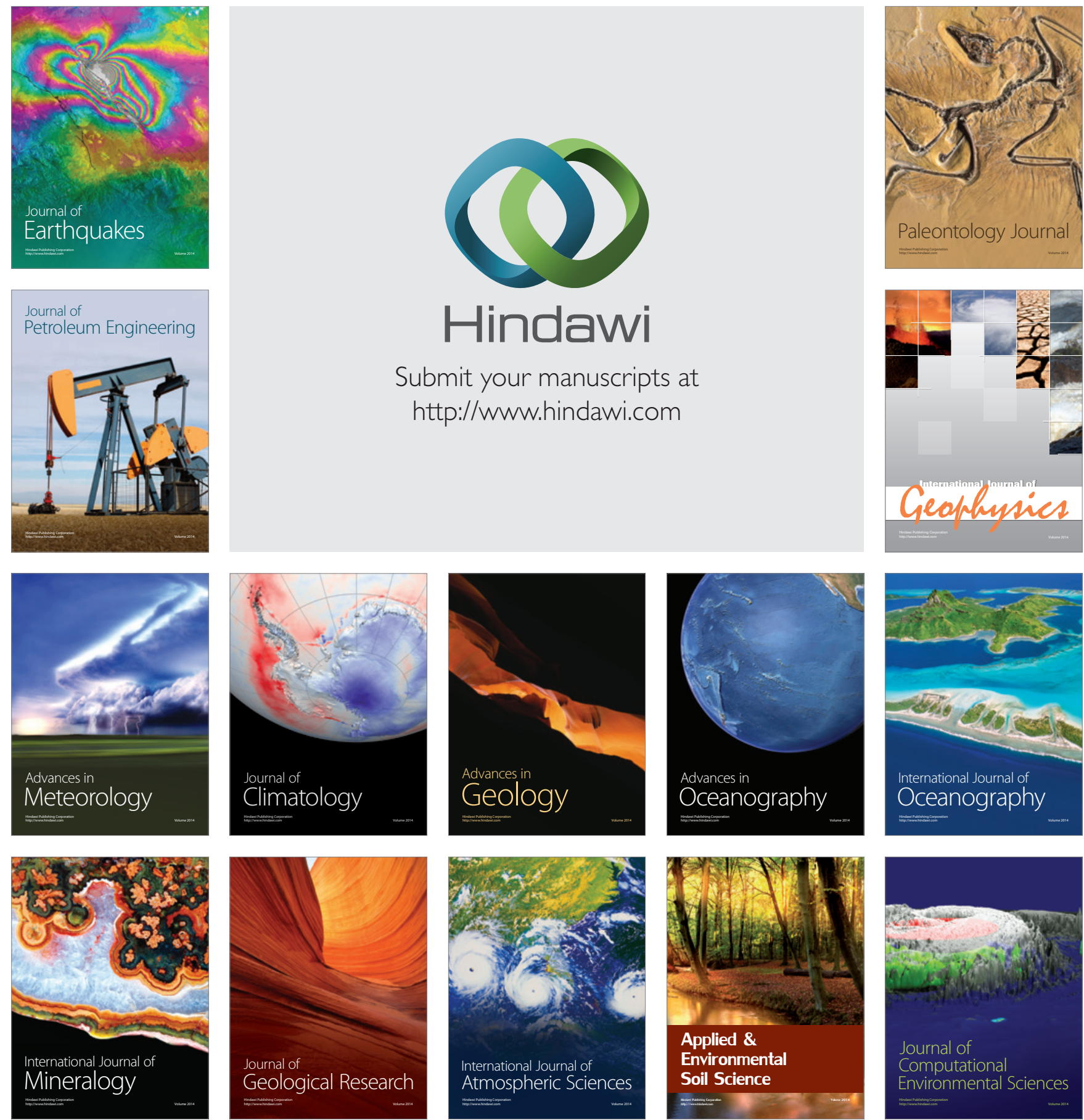